\title{
Beyond weight: examining the association of obesity with cardiometabolic related inpatient costs among Canadian adults using linked population based survey and hospital administrative data
}

Neeru Gupta* ${ }^{*}$ and Zihao Sheng ${ }^{2}$

\begin{abstract}
Background: The global population has transitioned to one where more adults are living with obesity than are underweight. Obesity is associated with the development of cardiometabolic diseases and widely attributed to increased hospital resource use; however, empirical evidence is limited regarding obesity prevention to support hospital cost containment. This study aims to test for obesity in predicting hospitalization costs for cardiometabolic conditions among the Canadian population aged 45 and over.

Methods: Data from the 2007-2011 Canadian Community Health Survey were linked to eight years of hospital discharge records. A cohort was identified of inpatients admitted for diabetes, hypertension, and other cardiometabolic diseases. Multiple linear regressions were used to investigate the association between obesity status and inpatient costs, controlling for sociodemographic and behavioural factors.

Results: The target cohort included 23,295 admissions for cardiometabolic diseases. Although inflation-adjusted inpatient costs generally increased over time, compared with the non-obese group, living with obesity was not a significant predictor of differences in cardiometabolic-related resource use $(0.972$ [95\% Cl: 0.926-1.021]). Being female and rural residence were found to be protective factors.

Conclusions: Obesity was not found in this study to be independently linked to higher cardiometabolic hospitalization costs, suggesting that actions to mitigate disease progression in the population may be more beneficial than simply promoting weight loss. Results amplified the need to consider gender and urbanization when formulating which levers are most amenable to adoption of healthy lifestyles to reduce impacts of obesogenic environments to the healthcare system.
\end{abstract}

Keywords: Obesity, Cardiometabolic health, Hospital costs, Demographic and health surveys, National hospital discharge surveys, Data linkage

\footnotetext{
*Correspondence: neeru.gupta@unb.ca

'Department of Sociology, University of New Brunswick, P.O. Box 4400, E3B

5 A3 Fredericton, New Brunswick, Canada

Full list of author information is available at the end of the article
}

(c) The Author(s). 2021 Open Access This article is licensed under a Creative Commons Attribution 4.0 International License, which permits use, sharing, adaptation, distribution and reproduction in any medium or format, as long as you give appropriate credit to the original author(s) and the source, provide a link to the Creative Commons licence, and indicate if changes were made. The images or other third party material in this article are included in the article's Creative Commons licence, unless indicated otherwise in a credit line to the material. If material is not included in the article's Creative Commons licence and your intended use is not permitted by statutory regulation or exceeds the permitted use, you will need to obtain permission directly from the copyright holder. To view a copy of this licence, visit http://creativecommons.org/licenses/by/4.0/ The Creative Commons Public Domain Dedication waiver (http://creativecommons.org/publicdomain/zero/1.0/) applies to the data made available in this article, unless otherwise stated in a credit line to the data. 


\section{Background}

The global population has transitioned to one where more people are living with obesity than are underweight [1]. In Canada, for example, obesity rates among adults nearly doubled over the past three decades, from $14 \%$ in 1978 to approximately $26 \%$ in 2013 [2]. These trends have been widely attributed to rapid urbanization and obesogenic environments, which may favour the adoption of unhealthy diets and sedentary behaviours $[3$, 4]. Obesity has been associated with higher incidence of chronic non-communicable diseases (NCDs) such as type 2 diabetes mellitus, ischemic heart disease, and related cardiometabolic complications and, in turn, increased risk of hospital admission, more frequent readmissions, and longer hospital stays [5-8]. At the same time, obesity is known to affect populations heterogeneously across clinical, sociodemographic, and behavioural characteristics [9-11]. Despite pervasive arguments that obesity is a key driver of growing healthcare expenditures for associated diseases, few studies have examined trends and determinants of hospital resource use and costs among persons living with obesity, especially ones including consideration of modifiable risk factors and drawing on nationally representative samples $[8,12-14]$. Much of the literature on the hospital burden of NCDs focuses on the characteristics of healthcare systems, such as access and clinical caregiving, or on patients' diagnosis-related complications, such as medical history and comorbidities [15-17]. It remains less well understood how sociodemographic and behavioural characteristics moderate the association between obesity and the hospital burden of cardiometabolic diseases.

Developments in the design of population-based studies have opened rich pathways for describing the role of sociodemographic factors on a range of health outcomes. In Canada, similar to many other countries, data linkages across population surveys and administrative information systems offer expanded opportunities to address research gaps on the sociodemographic correlates of common health problems and related impacts that would not be available from a single unlinked source [18-21]. The objective of this study was to examine the association of obesity with acute-care inpatient costs for cardiometabolic diseases, considering a range of other sociodemographic and behavioural characteristics. Acute inpatient care is one of the costliest categories to health systems. We take advantage of Canadian national household surveys linked with hospital administrative records to create a populationrepresentative study cohort. Since obesity is rarely recorded as the primary reason for hospitalization, we hypothesized that trends in hospital costs for cardiometabolic diseases will reflect a net combination of obesity and other patient characteristics.

\section{Methods}

\section{Data source}

This study drew on a unique resource of multiple years of data from the Canadian Community Health Survey (CCHS) linked to the hospital Discharge Abstract Database (DAD). Conducted annually by Statistics Canada, the CCHS collects demographic and health data from a nationally representative sample of approximately 65,000 household respondents aged 12 and over. The DAD contains routinely collected demographic, administrative, and diagnostic data by fiscal year of hospital separation for all acute-care admissions in 12 of the country's 13 jurisdictions (excluding the province of Quebec). Given the Canadian context of single-payer universal healthcare coverage, these data are considered a complete recording of all hospital stays. We pooled five years of CCHS cycles (2007-2011) with eight years of DAD datasets (2005/06-2012/13) to obtain sufficient sample sizes of cardiometabolic admissions. The survey and hospital data were matched using a probabilistic microdata linkage process based on individuals' birthdate, sex, and residential postal code [21, 22]. We limited our analysis to the population aged 45 and over, when the risk of hospitalization for NCDs increases and healthcare costs may reflect greater cumulative exposure to obesity [13]. The deidentified linkable datasets were accessed in the Statistics Canada Research Data Centre located at the University New Brunswick, in accordance with data privacy and security protocols.

\section{Outcome measure: cost of acute-care hospital stays}

The outcome variable for this study was the cost estimate for each acute-care hospitalization for cardiometabolic-related conditions, based on DAD data. Admissions for cardiometabolic conditions are generally considered ambulatory care sensitive, that is, potentially avoidable by interventions in primary and community care [23-25]. The diagnostic data in the DAD are coded to the International Classification of Diseases, 10th revision (ICD-10-CA) [26]. Following research elsewhere [27], all hospitalizations were included where the primary diagnosis for the length of stay was for diabetes and other metabolic diseases (ICD-10-CA codes E10E16, E70-E90), hypertensive diseases (I10I15), and cardio- and cerebro-vascular diseases (G08, G45, H34.0, H34.1, I20-I99). Using the methodology of the Canadian Institute for Health Information, hospital costs were estimated from aggregate information on the national cost of a standard stay applied to the resource intensity weight (RIW) for each DAD record [28]. The RIW reflects variations in expected resource use according to clinical and financial data, adjusted for patients' age group and comorbidities, relative to total acute inpatient expenditures. We applied the latest 2012/13 standard 
cost (in Canadian dollars) to all data to control for inflation and other differences in relative cost-efficiency across time and locations. Since patients may have had more than one hospital stay over the period of observation, the total costs reflected both single admissions and readmissions (although readmissions were statistically rare).

\section{Predictor variables}

The main predictor of interest was obesity status, based on self-reported height and weight information captured in the CCHS. We defined obesity status dichotomously from World Health Organization cut-offs for increased health risks: adults with a body mass index of at least $30 \mathrm{~kg} / \mathrm{m}^{2}$ were classified as living with obesity. Women who were pregnant at the time of the survey were excluded. While self-reported height and weight data may be subject to measurement error, studies have supported the validity of their use, citing lack of evidence of statistical superiority of direct anthropometric measures in population-based assessments of health outcomes [29, 30]. It is noted that underweight has also been associated with higher hospital resource use and costs; however, this has been attributable in the literature to non-cardiovascular causes [31]. Moreover, persons with obesity represent a disproportionate number in the Canadian population and therefore have a much greater impact on healthcare resource utilization. Studies have further reported that nonobese overweight may have negative impacts on health and healthcare expenditures, but the associations tend to be more modest compared with the effects of obesity [32]. The clinical and public health interest lies in the magnitude and wide range of the impacts of obesity at the population level [11].

Previous research using (unlinked) CCHS data highlights a complex relationship of obesity with sociodemographic and lifestyle factors [33, 34]. We further considered several potentially confounding factors including individuals' sex, age, place of residence (urban or rural), education (whether at least some postsecondary schooling was attained), physical activity (whether at least moderately active), dietary habits (number of daily consumptions of fruits and vegetables), tobacco use (whether currently smokes), and chronic disease status (whether reports having been told by a healthcare professional they had diagnosed diabetes, hypertension, or heart disease). Notably, some research has suggested that the association between obesity and hospital costs may differ between women and men $[35,36]$; however, a surprising number of published studies do not consider sex in the study design.

\section{Analytical approaches}

Our study conforms to the REporting of studies Conducted using Observational Routinely-collected health
Data (RECORD) protocol [37]. Following a brief descriptive analysis of the study population drawing on findings from the CCHS, we present a flow chart illustrating the selection of the target cohort from linking the survey data with the routine hospital records. Counts were rounded and adjusted to respect data confidentiality controls. The final cohort for analysis was limited to respondents with non-missing survey data for height/ weight and other predictors of interest. Although response rates for the $\mathrm{CCHS}$ are generally high, the nature of the distribution of non-responses for height/weight information is more uncertain [30].

Simple and multiple linear regressions were used to explore the role of obesity in explaining hospital costs for cardiometabolic diseases. The bivariate analyses considered key factors used to determine relative costs for acute inpatient care, notably, the length of stay (i.e., the number of days from admission to discharge) and the patients' comorbidity level (i.e., an index of the cumulative hospital care requirements and resource impact of comorbidities, including both pre-existing and hospitalinduced conditions) [38, 39]. The multiple regressions considered a range of patient-level sociodemographic and behavioural factors as potential confounders, and were further adjusted for the year of discharge. Individual characteristics at the time of the survey were assumed to represent those at the time of the hospital episode. All models were split by sex and used the logarithm of inpatient costs to reduce the effects of skewed data. The log transformation is widely applied in analyses of individual healthcare resource use and cost data; while certainly not the only methodological option, it was deemed appropriate for the present research given the policy interest, the absence of zero values (since only admitted patients were included), and the near-normality of the graphical representation following transformation (not shown due to privacy protocols) [40]. Regression parameters were estimated applying bootstrapped survey weights, to account for the complex CCHS sampling methods and ensure population representation of the results [41]. To ease interpretation, results are expressed in percentage terms of the predicted mean hospital cost difference by obesity status. All analyses were conducted using Stata v15, with confidence intervals (CIs) set at 95\%.

\section{Results}

\section{Study population}

Among the Canadian population 45 and over, 22\% (females: 23\%; males: 20\%) were living with obesity according to CCHS data (Fig. 1). Half (50\%) were physically inactive and 39\% reported having been diagnosed by a healthcare professional with diabetes $(11 \%)$, hypertension $(32 \%)$, or heart disease $(9 \%)$. The 


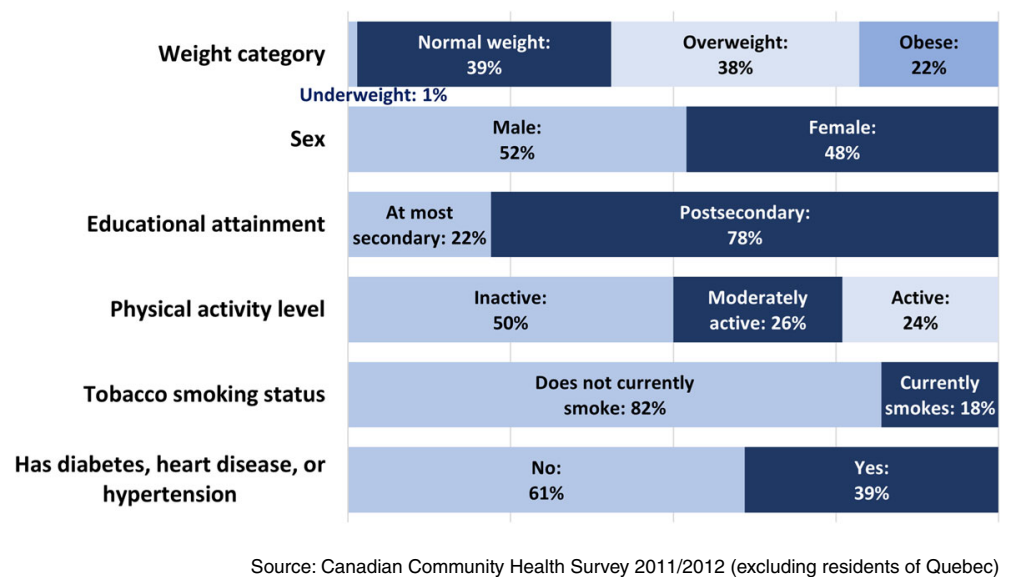

Fig. 1 Percentage distribution of the Canadian population aged 45 and over by selected sociodemographic and behavioural characteristics

frequency of fruits and vegetables consumption averaged 4.6 times a day (females: 5.0 times; males: 4.2 times), appreciably lower than national food intake recommendations for a healthy diet (not shown).

\section{Target cohort selection}

Five years of pooled CCHS data provided a sample of 320,371 household respondents, of whom 270,205 $(84.3 \%)$ agreed to have their data shared and linked with other databases (Fig. 2). Among these respondents, 120, $670(44.7 \%)$ were aged 45 and over and eligible for data linkage to the DAD. Their data were linked to 27,505 hospital admissions for cardiometabolic diseases over the period of observation. Following data linkage, 25,535 inpatient records (92.8\%) had valid information on obesity status and $23,295(84.7 \%)$ had valid information on all survey-based characteristics of interest. Of the final study cohort, 10,800 (46.4\%) were female and 12,485 (53.6\%) were male.

\section{Obesity and hospital costs}

Among the cohort under observation, based on simple regression analysis, obesity was not found to have influenced hospitalization costs for cardiometabolic diseases compared with the non-obese group: for both sexes combined, the relative mean cost difference was close to unity (0.970 [95\% CI: 0.928-1.015]) (Table 1).

Considering the sex-specific models, in the opposite direction from expected, male inpatients living with obesity averaged only $94 \%$ of the hospital costs of their non-obese counterparts (0.937 [95\% CI: 0.885-0.993]). No significant differences by obesity status in either mean length of stay or resource impact of comorbidities were observed which could potentially explain this pattern. Among women, no significant differences by obesity status in relative mean hospital cost $(1.018$ [95\% CI:
0.944-1.098]) or other clinical characteristics of hospitalizations were found.

Results of the multiple regression models

Results from the multiple linear regression for the total population revealed that acute-care costs for cardiometabolic conditions generally increased over time: compared with 2005/06, the cost averaged some 13\% higher in 2009/10 (1.132 [95\% CI: 1.043-1.229]) and 22\% higher in 2012/13 (1.225 [95\% CI: 1.108-1.353]) (Table 2, Model 1). Obesity was not found to be a significant predictor of cardiometabolic-related hospitalization costs $(0.972$ [95\% CI: $0.926-1.021])$. Rural residence was associated with approximately $7 \%$ less resource use compared with urbanity $(0.927$ [95\% CI: $0.887-$ 0.969]). As expected from established epidemiological patterns, inpatient costs increased significantly with age (1.004 [95\% CI: 1.001-1.006]), while being female was found to be a protective factor $(0.900$ [95\% CI: 0.860-0.942]). Patients' lifestyle factors, including indicators of diet and tobacco use, did not influence hospital costs, after controlling for other sociodemographics.

Splitting the analysis by gender, living with obesity was associated with significantly lower cardiometabolic inpatient costs among men $(0.934$ [95\% CI $=0.876-0.996])$ (Table 2, Model 3). No significant association between obesity status and hospitalization costs was found among women $(1.030$ [95\%CI $=0.949-1.117])$ (Table 2, Model 2). Younger age and rural residence were associated with lower inpatient costs for each sex.

\section{Discussion}

This study drew on multiple years of data from household surveys linked to acute-care hospital records to present, to our knowledge, the first Canadian population- 


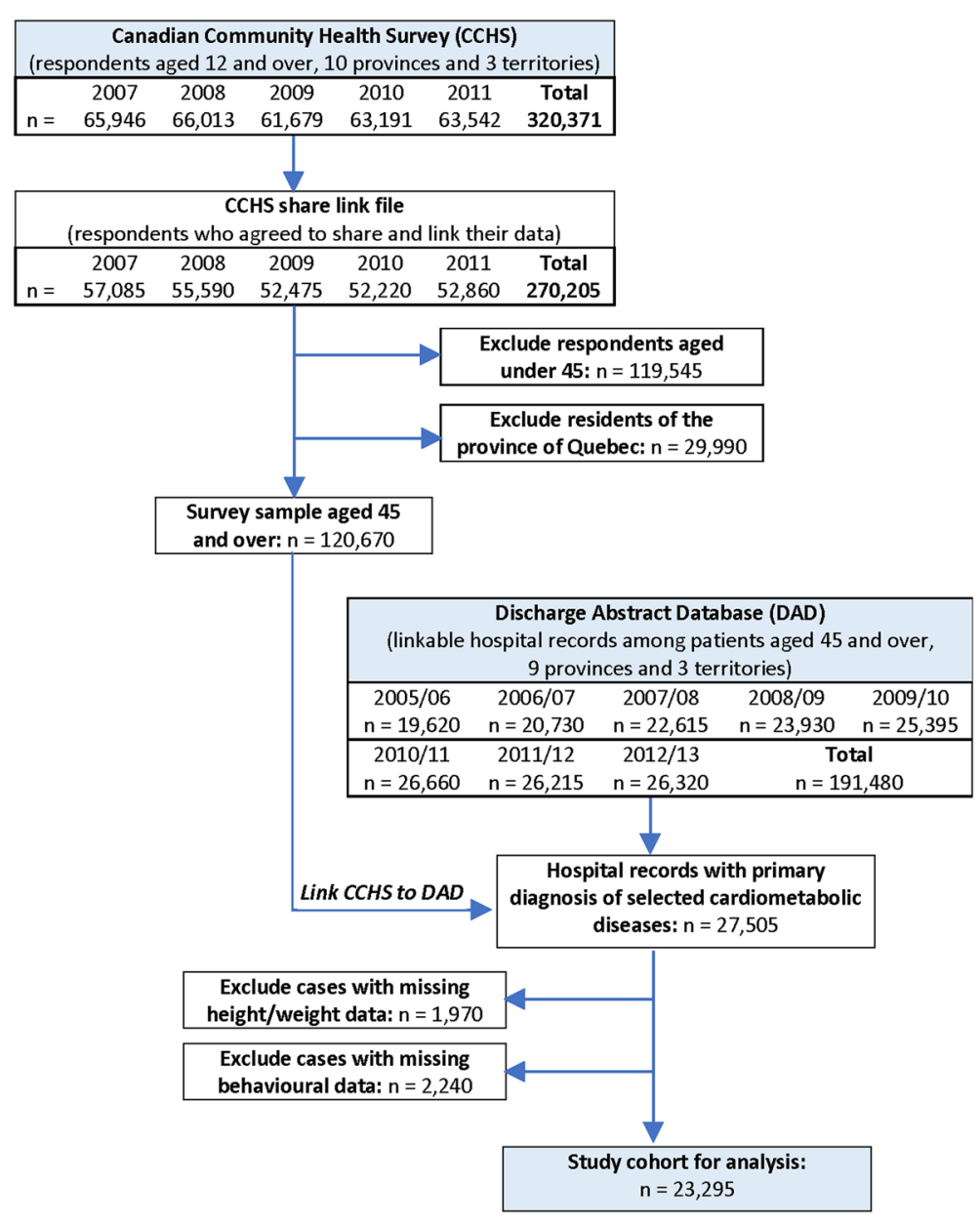

Note: Numbers may not add due to control rounding.

Fig. 2 Flow chart for the creation of the study cohort from linked survey and hospital data

representative investigation into the association of obesity status with cardiometabolic-related inpatient costs, as a summary indicator of disproportionate healthcare services resource use. We found that, while the inflation-adjusted costs for potentially avoidable hospitalizations for cardiometabolic diseases have been increasing over time, living with obesity was not distinguished as a significant cost predictor compared with those who were not obese $(0.972$ [95\% CI: 0.926-1.021]) among inpatients aged 45 and over, after controlling for a range of sociodemographic, behavioural, and health status indicators.

This result is consistent with research elsewhere indicating that the population living with obesity is not homogenous [10], and that obesity may not be significantly associated with higher healthcare costs independently of other behavioural factors associated with future risk of diabetes, hypertension, and related complications [42]. Obesity is widely defined in the literature in relation to body mass index; however, there is a lack of universally-accepted definition and metric for metabolically healthy obesity as an important subgroup, which different studies have assessed as representing from 6-75\% of the population living with obesity [43, 44]. The present findings thus support arguments that population-based actions to reduce the burden of obesity may be better placed focusing on interventions to reduce the risk of disease progression, rather than simply on reducing excess body weight at a given point in time [42, 45].

As expected, survey respondents reporting having been diagnosed with diabetes, heart disease, or hypertension averaged higher cardiometabolic-related hospital costs; it is possible, however, that some patients may have received their diagnosis during a hospital stay after interview. Urban residence was found to be associated with higher hospital costs compared with rural residence. Evidence on urban-rural differences in the hospital burden of obesity-associated NCDs is generally inconclusive; rural residency was found to have a negative association 
Table 1 Characteristics of acute-care hospitalizations for cardiometabolic diseases by obesity status of inpatients aged 45 and over, according to sex

\begin{tabular}{|c|c|c|c|c|c|c|c|c|c|}
\hline & \multicolumn{3}{|c|}{$\begin{array}{l}(1) \\
\text { Both sexes } \\
(n=25,535)\end{array}$} & \multicolumn{3}{|c|}{$\begin{array}{l}(2) \\
\text { Female } \\
(n=11,900)\end{array}$} & \multicolumn{3}{|c|}{$\begin{array}{l}(3) \\
\text { Male } \\
(n=13,635)\end{array}$} \\
\hline & $\beta$ & $95 \% \mathrm{Cl}$ & $p$-value & $\beta$ & $95 \% \mathrm{Cl}$ & $p$-value & $\beta$ & $95 \% \mathrm{Cl}$ & $p$-value \\
\hline \multicolumn{10}{|c|}{ Mean length of stay (days) } \\
\hline Living with obesity & 6.5 & $6.1-7.0$ & 0.25 & 7.1 & $6.3-7.9$ & 0.41 & 6.1 & $5.6-6.7$ & 0.38 \\
\hline Not obese & 6.3 & $6.0-6.5$ & & 6.7 & $6.3-7.2$ & & 5.9 & $5.6-6.2$ & \\
\hline \multicolumn{10}{|c|}{ Mean resource impact of comorbidities (comorbidity index) } \\
\hline Living with obesity & 9.1 & 7.7-10.5 & 0.83 & 9.7 & $7.8-11.6$ & 0.63 & 8.7 & $6.7-10.7$ & 0.54 \\
\hline Not obese & 8.9 & $8.1-9.8$ & & 10.2 & $8.9-11.5$ & & 8.1 & $6.9-9.2$ & \\
\hline \multicolumn{10}{|c|}{ Predicted mean cost difference (\%) } \\
\hline Living with obesity & 97.0 & $92.8-101.5$ & 0.19 & 101.8 & $94.4-109.8$ & 0.64 & $93.7 *$ & $88.5-99.3$ & 0.03 \\
\hline Not obese & -- & & & -- & & & -- & & \\
\hline
\end{tabular}

Note: * =significantly different from the non-obese group $(p<0.05) ; \mathrm{Cl}$ confidence interval. Predicted differences in mean cost by obesity status are based on simple log-linear regressions for all acute-care hospital stays (in constant Canadian dollars). All parameters are bootstrap weighted for population representation averaged over the period of observation

Source: 2007-2011 Canadian Community Health Survey linked to 2005/06-2012/13 Discharge Abstract Database

with the risk of diabetes-attributable readmissions in a study from the United States [46] but no significant association according to findings from Canada [19]. Somewhat unexpectedly, we did not find a significant association between smoking status and hospital costs. This result may be explained in part by survival selection bias inherent to observational studies among aging populations, due to higher pre-hospitalization mortality associated with tobacco use or other uncontrolled cardiometabolic risk factors $[47,48]$.

Based on split-sex regressions, we further found that obesity was independently associated with lower cardiometabolic hospital costs among men but not among women. Such results amplify the need to consider sex and gender when formulating which policy and practice levers are most amenable to the adoption of healthy lifestyles, notably in terms of weight stigma as a potential additional contributor to health disparities, especially among women. Obesity is identified in many societies as a highly stigmatizing personal attribute, one that may adversely affect medical compliance and implementation of healthy behaviours, and the risk of perceived interpersonal discrimination has been found to vary by gender and socioeconomic status [49].

Some limitations to this study should be noted. First, we focused on acute-care hospital costs, among the most expensive to health systems. While inpatient costs are considered essentially complete in this context of publicly-funded universal coverage, our analysis did not account for other direct and indirect costs for the treatment and management of NCDs, including services in primary and community-based care settings, emergency department visits that did not lead to admission, patients' out-of-pocket expenses such as non-insured medical equipment, or sickness absence from work, among others [50]. Second, obesity was categorized dichotomously from a cut-point for body mass index, rather than on a scale of body composition. The obesity phenotype is changing over time in Canada, with measures of body fat and fat distribution potentially contributing more to cardiometabolic morbidity in recent years than obesity prevalence [51]. Moreover, the need for more research on healthcare resource use among underweight patients has been identified [31]. Third, we only considered hospital costs for selected cardiometabolic diseases. Various other health problems that may result in hospitalization have been associated with obesity, such as osteoarthritis, back problems, and depression [5]. Fourth, obesity status was captured only once, at interview, which may raise concerns of reverse causality [18]. On the other hand, given the wider socioenvironmental influences hindering weight loss and its maintenance among adults, significant changes in weight categories in the shorter-term would seem unlikely.

\section{Conclusions}

Much of the health services literature on understanding the drivers of hospital costs has focused on measures of hospital infrastructure and healthcare system characteristics [15]. Advances in integrating different types of data platforms are supporting enhanced understanding of the trends, differentials, and risk factors underlying health outcomes and morbidity processes, especially among aging populations. This study adds to the literature recognizing the value of using linked population-based survey and administrative datasets to support research on 
Table 2 Adjusted coefficients (and 95\% confidence intervals) from the multiple linear regressions for predictors of acute-care costs for cardiometabolic diseases among inpatients aged 45 and over, according to sex

\begin{tabular}{|c|c|c|c|c|c|c|c|c|c|}
\hline & \multicolumn{3}{|c|}{$\begin{array}{l}(1) \\
\text { Both sexes } \\
(n=23,295)\end{array}$} & \multicolumn{3}{|c|}{$\begin{array}{l}(2) \\
\text { Female } \\
(n=10,800)\end{array}$} & \multicolumn{3}{|c|}{$\begin{array}{l}(3) \\
\text { Male } \\
(n=12,495)\end{array}$} \\
\hline & $\overline{\mathrm{e}^{\beta}}$ & $95 \% \mathrm{Cl}$ & $p$-value & $\overline{e^{\beta}}$ & $95 \% \mathrm{Cl}$ & $p$-value & $\overline{\mathrm{e}^{\beta}}$ & $95 \% \mathrm{Cl}$ & $p$-value \\
\hline \multicolumn{10}{|l|}{ Obesity status } \\
\hline Living with obesity (ref: Not obese) & 0.972 & $0.926-1.021$ & 0.25 & 1.030 & $0.949-1.117$ & 0.48 & $0.934^{*}$ & $0.876-0.996$ & 0.04 \\
\hline \multicolumn{10}{|l|}{ Sex } \\
\hline Female (ref: Male) & $0.900^{*}$ & $0.860-0.942$ & 0.00 & -- & & & -- & & \\
\hline \multicolumn{10}{|l|}{ Age } \\
\hline Years & $1.004^{*}$ & $1.001-1.006$ & 0.00 & $1.004^{*}$ & $1.001-1.007$ & 0.01 & $1.003^{*}$ & $1.000-1.007$ & 0.03 \\
\hline \multicolumn{10}{|l|}{ Place of residence } \\
\hline Rural (ref: Urban) & $0.927^{*}$ & $0.887-0.969$ & 0.00 & $0.918^{*}$ & $0.855-0.985$ & 0.02 & $0.937^{*}$ & $0.889-0.989$ & 0.02 \\
\hline \multicolumn{10}{|l|}{ Educational attainment } \\
\hline Postsecondary (ref: At most secondary) & 0.983 & $0.940-1.029$ & 0.47 & 0.965 & $0.903-1.032$ & 0.30 & 0.998 & $0.936-1.062$ & 0.95 \\
\hline \multicolumn{10}{|l|}{ Fruits and vegetables consumption } \\
\hline Times consumed daily & 1.007 & $0.998-1.017$ & 0.11 & 1.002 & $0.989-1.015$ & 0.73 & 1.011 & $0.998-1.023$ & 0.10 \\
\hline \multicolumn{10}{|l|}{ Physical activity level } \\
\hline Moderately active to active (ref: Not active) & 0.966 & $0.923-1.011$ & 0.14 & 0.961 & $0.899-1.027$ & 0.24 & 0.968 & $0.910-1.029$ & 0.30 \\
\hline \multicolumn{10}{|l|}{ Currently smokes tobacco } \\
\hline Yes (ref: No) & 1.042 & $0.972-1.116$ & 0.25 & 1.055 & $0.970-1.148$ & 0.21 & 1.031 & $0.933-1.139$ & 0.54 \\
\hline \multicolumn{10}{|l|}{ Has diabetes, heart disease, or hypertension } \\
\hline Yes (ref: No) & $1.079^{*}$ & $1.019-1.143$ & 0.01 & 1.064 & $0.987-1.148$ & 0.11 & $1.086^{*}$ & $1.003-1.176$ & 0.04 \\
\hline \multicolumn{10}{|l|}{ Year of hospital discharge } \\
\hline 2006/07 (ref: 2005/06) & 1.017 & $0.939-1.102$ & 0.68 & 1.036 & $0.926-1.161$ & 0.53 & 1.008 & $0.906-1.112$ & 0.88 \\
\hline $2007 / 08$ & 1.019 & $0.933-1.112$ & 0.68 & 1.066 & $0.923-1.232$ & 0.38 & 0.988 & $0.888-1.098$ & 0.82 \\
\hline 2008/09 & 1.087 & $0.999-1.183$ & 0.05 & 1.117 & $0.990-1.262$ & 0.07 & 1.073 & $0.960-1.119$ & 0.21 \\
\hline 2009/10 & $1.132^{*}$ & $1.043-1.229$ & 0.00 & $1.209^{*}$ & $1.065-1.372$ & 0.00 & 1.086 & $0.978-1.206$ & 0.12 \\
\hline 2010/11 & $1.109^{*}$ & $1.022-1.204$ & 0.01 & $1.114^{*}$ & $1.012-1.292$ & 0.03 & 1.092 & $0.979-1.217$ & 0.11 \\
\hline $2011 / 12$ & $1.156^{*}$ & $1.070-1.250$ & 0.00 & $1.200^{*}$ & $1.059-1.361$ & 0.00 & $1.132^{*}$ & $1.022-1.254$ & 0.02 \\
\hline 2012/13 & $1.225^{*}$ & $1.108-1.353$ & 0.00 & $1.214^{*}$ & $1.085-1.357$ & 0.00 & $1.243^{*}$ & $1.071-1.443$ & 0.00 \\
\hline
\end{tabular}

Note: ${ }^{*}=p<0.05$; ref reference group, $\mathrm{Cl}$ confidence interval. Parameters are estimated from log-linear regressions of the cost of acute-care hospital stays (in constant Canadian dollars), and bootstrap weighted for population representation

Source: 2007-2011 Canadian Community Health Survey linked to 2005/06-2012/13 Discharge Abstract Database

obesity as a hypothesized key risk factor for hospital resource use and costs, since weight and other patient characteristics are not routinely captured in administrative hospital discharge records. Obesity was not found to be a significant driver of cardiometabolic-related hospital costs among the Canadian population aged 45 and over, after controlling for sociodemographic and behavioural factors, thus raising questions as to whether obesity prevention alone is an efficient hospital cost containment measure. The present findings fuel increasingly widespread arguments to prioritize interventions aimed at mitigating the risk of chronic disease progression, rather than simply focusing on weight loss to reduce the burden of obesity.
Abbreviations

CCHS: Canadian Community Health Survey; Cl: confidence interval; DAD: Discharge Abstract Database; ICD-10: International Classification of Diseases, 10th revision; NCD: non-communicable disease; RECORD: REporting of studies Conducted using Observational Routinely-collected health Data; RIW: resource intensity weight

\section{Acknowledgements}

The authors wish to thank Sarah Fowler for research assistance with literature reviews and Qinglin Yan for assistance with statistical descriptions. The data analysis was conducted at the New Brunswick Research Data Centre (NBRDC), which is part of the Canadian Research Data Centre Network. The services and activities provided by the NB-RDC are made possible by the financial or in-kind support of the Social Sciences and Humanities Research Council, the Canadian Institutes of Health Research, the Canadian Foundation for Innovation, Statistics Canada, and the University of New Brunswick. Some 
preliminary findings from this research were presented at the International Health Economics Association 2019 World Congress (13-17 July 2019, Basel, Switzerland)

\section{Authors' contributions}

NG conceptualized the study and led the writing of the manuscript. ZS performed the data management and formal analysis. All authors contributed to interpreting the results. All authors read and approved the final manuscript.

\section{Funding}

This study received financial support from Diabetes Canada, the New Brunswick Health Research Foundation, the Heart and Stroke Foundation of New Brunswick, and the University of New Brunswick. The funders had no role in the study design, data analysis, results interpretation, or decision to submit the manuscript for publication.

\section{Availability of data and materials}

The data that support the findings of this study are available from Statistics Canada but restrictions apply to the availability of these data, which were used under license for the current study, and so are not publicly available.

\section{Ethics approval and consent to participate}

This study complied with the Research Ethics Board of the University of New Brunswick (Fredericton, Canada), which does not require an internal institutional review for research projects using datasets accessed through the New Brunswick Research Data Centre.

\section{Consent for publication}

Not applicable.

\section{Competing interests}

The authors declare that they have no competing interests.

\section{Author details}

'Department of Sociology, University of New Brunswick, P.O. Box 4400, E3B 5A3 Fredericton, New Brunswick, Canada. ${ }^{2}$ Department of Economics, Dalhousie University, Halifax, Canada.

Received: 3 August 2020 Accepted: 28 December 2020

Published online: 11 January 2021

\section{References}

1. NCD Risk Factor Collaboration. Trends in adult body-mass index in 200 countries from 1975 to 2014: a pooled analysis of 1698 population-based measurement studies with 19.2 million participants. Lancet. 2016;387(10026): 1377-96.

2. Bancej C, Jayabalasingham B, Wall RW, Rao DP, Do MT, de Groh M, et al. Trends and projections of obesity among Canadians. Health Promot Chronic Dis Prev Can. 2015;35(7):109-12.

3. Rosengren A, Teo K, Rangarajan S, Kabali C, Khumalo I, Kutty VR, et al. Psychosocial factors and obesity in 17 high-, middle- and low-income countries: the Prospective Urban Rural Epidemiologic study. Int J Obes 2015:39(8):1217-23.

4. Roberto CA, Swinburn B, Hawkes C, Huang $\Pi T-K$, Costa SA, Ashe M, et al. Patchy progress on obesity prevention: emerging examples, entrenched barriers, and new thinking. Lancet. 2015;385(9985):2400-9.

5. Han E, Truesdale KP, Taber DR, Cai J, Juhaeri J, Stevens J. Impact of overweight and obesity on hospitalization: race and gender differences. Int J Obes. 2009;33(2):249-56.

6. Schafer MH, Ferraro KF. Obesity and hospitalization over the adult life course: Does duration of exposure increase use? J Health Soc Behav. 2007; 48(4):434-49.

7. Vellinga A, O'Donovan D, De La Harpe D. Length of stay and associated costs of obesity related hospital admissions in Ireland. BMC Health Serv Res. 2008;8(1):88

8. Zizza C, Herring AH, Stevens J, Popkin BM. Length of hospital stays among obese individuals. Am J Public Health. 2004;94(9):1587-91.

9. Doblhammer G, Hoffmann R, Muth E, Westphal C, Kruse A. A systematic literature review of studies analyzing the effect of sex, age, education, marital status, obesity, and smoking on health transitions. Demogr Res. 2009:20:37-64.

10. Jimenez MP, Green MA, Subramanian SV, Razak F. A demographic, clinical, and behavioral typology of obesity in the United States: an analysis of National Health and Nutrition Examination Survey 2011-2012. Ann Epidemiol. 2018;28(3):175-81.e4.

11. Janssen I. The public health burden of obesity in Canada. Can J Diabetes. 2013;37(2):90-6.

12. Larg A, Moss JR, Spurrier N. Relative contribution of overweight and obesity to rising public hospital in-patient expenditure in South Australia. Aust Health Rev. 2019;43(2):148.

13. Tsai AG, Williamson DF, Glick HA. Direct medical cost of overweight and obesity in the USA: a quantitative systematic review. Obes Rev. 2011;12(1):50-61.

14. Withrow D, Alter DA. The economic burden of obesity worldwide: a systematic review of the direct costs of obesity. Obes Rev. 2011:12(2):131-41.

15. Buttigieg SC, Abela L, Pace A. Variables affecting hospital length of stay: a scoping review. J Health Organ Manag. 2018;32(3):463-93.

16. Huang Y-C, Hu C-J, Lee T-H, Yang J-T, Weng H-H, Lin LC, et al. The impact factors on the cost and length of stay among acute ischemic stroke. $J$ Stroke Cerebrovasc Dis. 2013;22(7):e152-8.

17. Lopez-de-Andres A, Carrasco-Garrido P, Esteban-Hernandez J, Gil-de-Miguel Á, Jiménez-García R. Characteristics and hospitalization costs of patients with diabetes in Spain. Diabetes Res Clin Pract. 2010;89(1):e2-4.

18. Devillanova C, Raitano M, Struffolino E. Longitudinal employment trajectories and health in middle life: insights from linked administrative and survey data. Demogr Res. 2019;40(47):1375-412.

19. Gupta N, Crouse DL. Social disparities in the risk of potentially avoidable hospitalization for diabetes mellitus: an analysis with linked census and hospital data. Can Stud Popul. 2019;46(2):145-59.

20. Mah SM, Sanmartin C, Harper S, Ross NA. Childbirth-related hospital burden by socioeconomic status in a universal health care setting. Int J Popul Data Sci. 2018:3(12):1-20.

21. Rotermann M. High use of acute care hospital services at age 50 or older. Health Rep. 2017:28(82):16. PMID: 28930363.

22. Ramage-Morin PL, Gilmour H, Rotermann M. Nutritional risk, hospitalization and mortality among community-dwelling Canadians aged 65 or older. Health Rep. 2017;28(82):13. PMID: 28930364

23. Billings J, Zeitel L, Lukomnik J, Carey TS, Blank AE, Newman L. Impact of socioeconomic status on hospital use in New York City. Health Aff (Millwood). 1993:12(1):162-73.

24. Dantas I, Santana R, Sarmento J, Aguiar P. The impact of multiple chronic diseases on hospitalizations for ambulatory care sensitive conditions. BMC Health Serv Res. 2016;16(1):348.

25. Gibson OR, Segal L, McDermott RA. A systematic review of evidence on the association between hospitalisation for chronic disease related ambulatory care sensitive conditions and primary health care resourcing. BMC Health Serv Res. 2013;13(336):1-13.

26. Canadian Institute for Health Information. International Statistical Classification of Diseases and Related Health Problems, Tenth Revision (ICD10-CA). Ottawa: Canadian Institute for Health Information; 2009. p. 1068

27. Gupta N, Sheng Z. Disparities in the hospital cost of cardiometabolic diseases among lesbian, gay, and bisexual Canadians: a population-based cohort study using linked data. Can J Public Health. 2020;111(3):417-25.

28. Canadian Institute for Health Information. Canadian Patient Cost Database Technical Document: MIS Patient Costing Methodology, March 2017. Ottawa: Canadian Institute for Health Information; 2017. p. 58

29. Davies A, Wellard-Cole L, Rangan A, Allman-Farinelli M. Validity of selfreported weight and height for BMI classification: a cross-sectional study among young adults. Nutrition. 2020;71:110622.

30. Dutton DJ, McLaren L. The usefulness of "corrected" body mass index vs. selfreported body mass index: comparing the population distributions, sensitivity, specificity, and predictive utility of three correction equations using Canadian population-based data. BMC Public Health. 2014;14(430):1-11.

31. Johnson AP, Parlow JL, Milne B, Whitehead M, Xu J, Rohland S, et al. Economies of scale: body mass index and costs of cardiac surgery in Ontario, Canada. Eur J Health Econ. 2017;18(4):471-9.

32. Kivimäki M, Kuosma E, Ferrie JE, Luukkonen R, Nyberg ST, Alfredsson L, et al. Overweight, obesity, and risk of cardiometabolic multimorbidity: pooled analysis of individual-level data for 120813 adults from 16 cohort studies from the USA and Europe. Lancet Public Health. 2017:2(6):e277-85. 
33. Godley J, McLaren L. Socioeconomic status and body mass index in Canada: exploring measures and mechanisms. Can Rev Sociol. 2010;47(4):381-403.

34. Slater J, Green C, Sevenhuysen G, O'Nail J, Ediginton B. Socio-demographic and geographic analysis of overweight and obesity in Canadian adults using the Canadian Community Health Survey (2005). Chronic Dis Can. 2009:30(1):3-14.

35. Borg S, Persson U, Ödegaard K, Berglund G, Nilsson J-Å, Nilsson PM. Obesity, survival, and hospital costs-Findings from a screening project in Sweden. Value Health. 2005;8(5):562-71.

36. Folmann NB, Bossen KS, Willaing I, Sørensen J, Andersen JS, Ladelund S, et al. Obesity, hospital services use and costs. Adv Health Econonics Health Serv Res. 2007;17:319-32.

37. Benchimol El, Smeeth L, Guttmann A, Harron K, Moher D, Petersen I, et al. The REporting of studies Conducted using Observational Routinelycollected health Data (RECORD) Statement. PLOS Med. 2015;12(10): e1001885.

38. Canadian Institute for Health Information. DAD Data Elements 2015-2016. Ottawa: Canadian Institute for Health Information; 2016. p. 25.

39. Chu F, Ohinmaa A, Kaul P. Canadian case mixed groups (CMG+) costing proxy for acute myocardial infarction. J Health Med Econ. 2016;2(8):1-4.

40. Mihaylova B, Briggs A, O'Hagan A, Thompson SG. Review of statistical methods for analysing healthcare resources and costs. Health Econ. 2011; 20(8):897-916.

41. Thomas S, Wannell B. Combining cycles of the Canadian Community Health Survey. Health Rep. 2009;20(1):1-7. PMID: 19388369.

42. Alter DA, Wijeysundera $\mathrm{HC}$, Franklin B, Austin PC, Chong A, Oh PI, et al. Obesity, lifestyle risk-factors, and health service outcomes among healthy middle-aged adults in Canada. BMC Health Serv Res. 2012;12(238):1-12.

43. Rey-López JP, de Rezende LF, Pastor-Valero M, Tess BH. The prevalence of metabolically healthy obesity: a systematic review and critical evaluation of the definitions used. Obes Rev. 2014;15(10):781-90.

44. Roberson LL, Aneni EC, Maziak W, Agatston A, Feldman T, Rouseff M, et al. Beyond BMI: The "metabolically healthy obese" phenotype \& its association with clinical/subclinical cardiovascular disease and all-cause mortality - a systematic review. BMC Public Health. 2014;14(1):14.

45. Stefan N, Häring H-U, Schulze MB. Metabolically healthy obesity: the low-hanging fruit in obesity treatment? Lancet Diabetes Endocrinol. 2018;6(3):249-58.

46. Bennett KJ, Probst JC, Vyavaharkar M, Glover SH. Lower rehospitalization rates among rural Medicare beneficiaries with diabetes. J Rural Health. 2012; 28(3):227-34.

47. Banack HR, Harper S, Kaufman JS. Accounting for selection bias in studies of acute cardiac events. Can J Cardiol. 2018;34(6):709-16.

48. Banack HR, Kaufman JS, Wactawski-Wende J, Troen BR, Stovitz SD. Investigating and remediating selection bias in geriatrics research. J Am Geriatr Soc. 2019;67(9):1970-6.

49. Hansson LM, Näslund E, Rasmussen F. Perceived discrimination among men and women with normal weight and obesity. A population-based study from Sweden. Scand J Public Health. 2010:38(6):587-96.

50. Tremmel M, Gerdtham U-G, Nilsson P, Saha S. Economic burden of obesity: a systematic literature review. Int J Environ Res Public Health. 2017;14(435):1-18

51. Janssen I, Shields M, Craig CL, Tremblay MS. Changes in the obesity phenotype within Canadian children and adults, 1981 to 2007-2009. Obesity. 2012;20(4):916-9.

\section{Publisher's Note}

Springer Nature remains neutral with regard to jurisdictional claims in published maps and institutional affiliations.

Ready to submit your research? Choose BMC and benefit from:
- fast, convenient online submission
- thorough peer review by experienced researchers in your field
- rapid publication on acceptance
- support for research data, including large and complex data types
- gold Open Access which fosters wider collaboration and increased citations
- maximum visibility for your research: over 100M website views per year
At BMC, research is always in progress.
Learn more biomedcentral.com/submissions

